\title{
Requirement of aquaporin-1 for NaCl-driven water transport across descending vasa recta
}

\author{
Thomas L. Pallone, ${ }^{1}$ Aurélie Edwards, ${ }^{2}$ Tonghui Ma, ${ }^{3}$ Erik P. Silldorff, ${ }^{4}$ and A.S. Verkman ${ }^{3}$ \\ ${ }^{1}$ Division of Nephrology, University of Maryland School of Medicine, Baltimore, Maryland 21201, USA \\ ${ }^{2}$ Department of Chemical Engineering, Tufts University, Medford, Massachusetts 02155, USA \\ ${ }^{3}$ Cardiovascular Research Institute, University of California-San Francisco, San Francisco, California 94143, USA \\ ${ }^{4}$ Department of Biology, Towson University, Towson, Maryland 21252, USA
}

Address correspondence and reprint requests to: Thomas L. Pallone, Division of Nephrology, University of Maryland-Baltimore, 22 S. Greene Street, N3W143, Baltimore, Maryland 21201-1595, USA.

Phone: (410) 328-5720; Fax: (410) 328-5685; E-mail: tpallone@medicine.umaryland.edu.

Received for publication August 19, 1999, and accepted in revised form November 16, 1999.

Deletion of $A Q P 1$ in mice results in diminished urinary concentrating ability, possibly related to reduced $\mathrm{NaCl}$ - and urea gradient-driven water transport across the outer medullary descending vasa recta (OMDVR). To quantify the role of AQP1 in OMDVR water transport, we measured osmotically driven water permeability in vitro in microperfused OMDVR from wild-type, $A Q P 1$ heterozygous, and $A Q P 1$ knockout mice. OMDVR diameters in $A Q P 1^{-/-}$mice were 1.9-fold greater than in $A Q P 1^{+/+}$mice. Osmotic water permeability $\left(\mathrm{P}_{\mathrm{f}}\right)$ in response to a $200 \mathrm{mM} \mathrm{NaCl}$ gradient (bath > lumen) was reduced about 2 -fold in $A Q P 1^{+/-}$mice and by more than 50 -fold in $A Q P 1^{-/-}$mice. $P_{\mathrm{f}}$ increased from 1015 to $2527 \mu \mathrm{m} / \mathrm{s}$ in $A Q P 1^{+/+}$ mice and from 22 to $1104 \mu \mathrm{m} / \mathrm{s}$ in $A Q P 1^{-/-}$mice when a raffinose rather than an $\mathrm{NaCl}$ gradient was used. This information, together with $p$-chloromercuribenzenesulfonate inhibition measurements, suggests that nearly all $\mathrm{NaCl}$-driven water transport occurs by a transcellular route through $\mathrm{AQP} 1$, whereas raffinose-driven water transport also involves a parallel, AQP1-independent, mercurial-insensitive pathway. Interestingly, urea was also able to drive water movement across the AQP1-independent pathway. Diffusional permeabilities to small hydrophilic solutes were comparable in $A Q P 1^{+/+}$and $A Q P 1^{-/-}$mice but higher than those previously measured in rats. In a mathematical model of the medullary microcirculation, deletion of AQP1 resulted in diminished concentrating ability due to enhancement of medullary blood flow, partially accounting for the observed urine-concentrating defect.

J. Clin. Invest. 105:215-222 (2000).

\section{Introduction}

It is generally believed that the microcirculation of the renal medulla traps $\mathrm{NaCl}$ and urea by countercurrent exchange, in order to preserve corticomedullary gradients generated by the loops of Henle and the collecting duct (1). Details of the complex tubular vascular relationships of the medulla and the recent delineation of transport pathways across the vasa recta walls have advanced our understanding of the countercurrent exchange mechanism (2-6). With respect to the transport of water, classical Starling forces (hydraulic and oncotic pressure) can drive water flux across outer medullary descending vasa recta (OMDVR) via a shared pathway where small hydrophilic solutes are also transported (6). In vivo, however, it has been shown that water efflux occurs across the descending vasa recta (DVR) wall at some location between the corticomedullary junction and papillary tip, despite the existence of Starling forces that favor volume influx (7). It was proposed that water efflux involves a water-only pathway in which $\mathrm{NaCl}$ and urea gradients are able to drive water movement, and that the water-only pathway might comprise aquaporin-1 (AQP1) water channels $(8,9)$.

The recently created $A Q P 1$ knockout mouse provides a tool for delineating the role of AQP1 in OMDVR water transport. The knockout mice were generated by targeted gene disruption, and were shown to manifest a severe urinary concentrating defect associated with defective medullary interstitial osmolality (10) and defective nearisosmolar fluid reabsorption in proximal tubule (11). The $A Q P 1$ knockout mice are polyuric, yet when given free access to food and water appear to be grossly normal except for mild growth retardation compared with littermatched wild-type mice. Based on the expression of AQP1 outside the kidney, several extrarenal phenotypes have been reported, including defective lung fluid transport (12).

The purpose of this study was to define the role of AQP1 in OMDVR water transport. An in vitro microperfusion technique that was originally developed to measure water and solute transport in rat kidney OMDVR was adapted to the mouse. We found that OMDVR of wildtype mice have an osmotic water permeability $\left(\mathrm{P}_{\mathrm{f}}\right)$ similar to that of rats $(\sim 1,100 \mu \mathrm{m} / \mathrm{s})$. In contrast, OMDVR of $A Q P 1^{-/-}$mice have a near-zero $\mathrm{P}_{\mathrm{f}}$ when water flux is driven by transmural $\mathrm{NaCl}$ gradients. Interestingly, OMDVR from $A Q P 1^{-/-}$mice transport significant quantities of water across a mercurial-insensitive pathway when the osmotic gradient is produced by other small solutes, including urea. Our data define the role of AQP1 in the renal microvasculature, and support the conclusion that 
AQP1-mediated water efflux across OMDVR is required for effective countercurrent exchange.

\section{Methods}

Transgenic mice. AQP1 knockout mice were generated by targeted gene disruption as described previously (10). The mice expressed no full-length $A Q P 1$ transcript and no AQP1 protein in any tissue. Genotype analysis was performed at age 5 days. Experiments were carried out on litter-matched wild-type $\left(A Q P 1^{+/+}\right)$, heterozygous $\left(A Q P 1^{+/-}\right)$ and knockout $\left(A Q P 1^{--}\right)$mice produced by breeding of $A Q P 1^{+/-}$mice.

Microperfusion. The methods used to dissect and perfuse OMDVR from mice were adapted from those developed in rats (4). OMDVR were dissected from outer medullary vascular bundles, and then mounted on pipettes and fixed with $1 \%$ glutaraldehyde (GA) for 10-20 seconds. The GA fixation step is necessary because large osmotic gradients cause deterioration of endothelial cells, as does exposure to $p$-chloromercuribenzenesulfonate (pCMBS) (8). In agreement with investigations in toad bladders and nephron segments $(13,14)$, we have shown that GA fixation preserves $\mathrm{Na}$ permeability, diffusional water permeability, and $\mathrm{P}_{\mathrm{f}}$ of $\mathrm{OMDVR}(2,8)$. OMDVR were mounted and perfused on concentric pipettes, and flow rates were determined by timed collection with volumetric constriction pipettes $(\sim 70 \mathrm{~nL})$. For in vitro microperfusion, dissected OMDVR were perfused and bathed in a solution of $5 \mathrm{mM}$ HEPES, $150 \mathrm{mM} \mathrm{NaCl}, 10 \mathrm{mM} \mathrm{Na}$ acetate, $5 \mathrm{mM}$ $\mathrm{KCl}, 1.2 \mathrm{mM} \mathrm{MgCl}, 1.71 \mathrm{mM} \mathrm{Na} \mathrm{HPO}_{4}, 0.29 \mathrm{mM}$ $\mathrm{NaH}_{2} \mathrm{HPO}_{4}, 1 \mathrm{mM} \mathrm{CaCl}, 5 \mathrm{mM}$ alanine, $5 \mathrm{mM}$ glucose, and $0.5 \mathrm{~g} / \mathrm{dL}$ albumin, adjusted to $\mathrm{pH}$ 7.4. To drive osmotic water efflux across the OMDVR wall, the bath was made hypertonic to the lumen by adding specified concentrations of $\mathrm{NaCl}$, raffinose, glucose, or urea to the bathing solution. In some experiments, microperfused OMDVR were incubated with $2 \mathrm{mM}$ pCMBS or $5 \mathrm{mM}$ DTT. Albumin was eliminated from the buffer during those incubation periods. Tracer concentrations of radioisotopes were used to measure diffusive equilibration in most experiments. Activity of isotopes in the perfusate and collectate was measured with an LS6500 beta counter (Beckman Instruments Inc., Columbia, Maryland, USA). FITClabeled dextran (FITCDx; $2 \times 10^{6} \mathrm{~mol} \mathrm{wt} ; 0.5 \mathrm{mg} / \mathrm{mL}$ ) was included in the perfusate as a volume marker and was measured fluorimetrically.

Volume flux and permeability measurement. Volume efflux $\left(Q_{v}\right)$ from the microperfused OMDVR was calculated from the rate of collection $\left(Q_{c}\right)$ and collectate-to-perfusate concentration ratio $\left(R_{\mathrm{Dx}}\right)$ of FITCDx: $Q_{\mathrm{v}}=Q_{\mathrm{c}}\left(R_{\mathrm{Dx}}-1\right)$ (ref. 4). FITCDx fluorescence was continuously monitored in the collection pipette inlet as a means of measuring transmural water movement. FITC was excited at $485 \mathrm{~nm}$ using a xenon lamp, a bandpass filter, and a 505-nm dichroic mirror (Omega Optical Inc., Brattleboro, Vermont, USA). Emitted fluorescence was filtered by a $535-\mathrm{nm}$ bandpass filter and detected using a D108 photon-counting detection assembly (Photon Technology International Inc., South Brunswick, New Jersey, USA). This method for measuring volume flux has been described previously (8). We have verified that increasing buffer concentration of $\mathrm{NaCl}$ from 150 to $350 \mathrm{mM}$ has little effect on $\mathrm{pH}(<0.02$ units) or FITCDx volume-marker fluorescence (<0.3\%).

Solute diffusional permeabilities $\left(P_{i}\right)$ were calculated from the collectate-to-perfusate ratio of tracer activity $\left(R^{*}{ }_{i}\right)$, vessel diameter $(D)$, vessel length $(L)$, and $Q_{\mathrm{c}}$ under zero volume flux conditions (symmetrical bath and perfusate) using the equation $P_{i}=\left(Q_{c} / \pi D L\right) \ln \left(R^{*}{ }_{i}\right)$ (ref. 4).

Microanalysis of chloride. In some experiments, the equilibration of $\mathrm{NaCl}$ between bath and lumen was measured by microassay of chloride concentration using a continuous flow microcolorimeter. Chloride reagent (Kit 461, Sigma Chemical Co., St. Louis, Missouri, USA) was drawn through the system at a rate of $5 \mu \mathrm{L} / \mathrm{min}$. Samples for injection were placed in an acrylic trough under mineral oil so that successive volumes $(0.8 \mathrm{~nL})$ could be dispensed from a volumetric constriction pipette into the flowing reagent stream. The reaction creates a ferric thiocyanate reaction product that absorbs light at $460 \mathrm{~nm}$. Output and linearity of the device have been described (8).

Calculation of $P_{f} . P_{\mathrm{f}}$ was computed from measured water flux across the microvessel wall and the imposed osmotic gradient. As described above, water flux was determined from the concentration of the FITCDx volume marker. The dissipation of the transmural solute gradient along the axis of the microperfused vessel was measured by microcolorimetry of perfusate and collectate chloride, or was calculated with a mathematical model by simulating measured isotopic solute fluxes. These approaches have been validated and shown to yield identical results $(8,9)$. As will be shown, an important finding of this work is that water transport can be driven across the OMDVR wall by small hydrophilic solutes across at least 2 pathways: through AQP1, with osmotic water permeability $\mathrm{P}_{\mathrm{f} 1}$, and through a second mercurial-insensitive pathway, $\mathrm{P}_{\mathrm{f} 2}$. Because the experiments described in this paper involve axial gradients of permeant and impermeant solutes as well as coupled water-solute flow through more than 1 transmural pathway, mathematical analysis was required to deduce transport parameters from the experimental data. $\mathrm{NaCl}$ is present in the bath and lumen of all experiments. Other small hydrophilic solutes have been used to induce water flux (urea, glucose, raffinose) or added as tracers to the perfusate to measure permeability and molecular sieving $\left({ }^{22} \mathrm{Na},\left[{ }^{14} \mathrm{C}\right]\right.$ urea, $\left[{ }^{3} \mathrm{H}\right]$ glucose, $\left[{ }^{3} \mathrm{H}\right]$ raffinose, $\left[{ }^{3} \mathrm{H}\right]$ inulin). Conservation equations are defined in terms of the luminal volume flow rate $(Q)$, concentrations of sodium $\left(C_{\mathrm{Na}}\right)$, and the $i^{\text {th }}$ solute $\left(C_{\mathrm{i}}\right)$ by
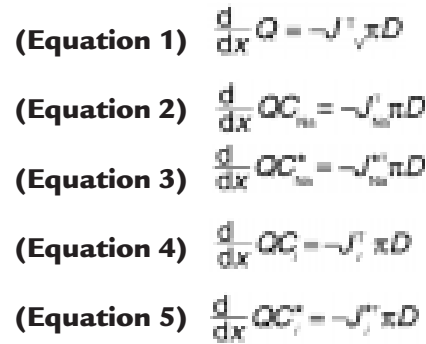

where $\int^{\mathrm{T}} \mathrm{Na}$ and $J^{\mathrm{T}}$ are the total sum of fluxes of $\mathrm{Na}$ and the 
solute $i$, respectively; through all pathways, the superscript “*” refers to the isotopic form of the solute, and $D$ is vessel diameter.

Our results indicate that at least 2 pathways contribute to volume and solute flux across the OMDVR wall. First, AQP1 is pCMBS sensitive, conducts water flux, and is presumed to completely restrict the passage of solutes. We designate AQP1 as pathway 1 whose osmotic water permeability is $\mathrm{P}_{\mathrm{f} 1}$, solute permeability is zero, and reflection coefficient to all solutes is $1\left(J_{\mathrm{Na} 1}=\right.$ $\left.J_{i 1}=0\right)$. A second pCMBS-insensitive pathway is present that also conducts volume flux across the OMDVR wall when the molecular weight of the driving solute is greater than that of $\mathrm{NaCl}$. Pathway 2 is defined by osmotic water permeability $\mathrm{P}_{\mathrm{f} 2}$, solute permeabilities $\mathrm{P}_{i 2}$, and reflection coefficients $\sigma_{2, i}>0$ and $\sigma_{2, \mathrm{Na}}=0$.

We have shown previously that transmural hydraulic pressure in microperfused OMDVR is low (15). Since perfusate albumin is only $0.5 \mathrm{~g} / \mathrm{dL}$, Starling forces are negligible and volume fluxes are defined by

(Equation 6) $S_{n}=V P_{n}\left[\left(C_{n, j}-C_{v}\right)+\left(C_{m}-C\right)\right]$

(Equation 7) $J_{v e}=V P_{N 2} \sigma_{2}\left(C_{w}-C_{1}\right)$

where $V_{\mathrm{w}}$ is the partial molar volume of water and the additional subscript " $\mathrm{B}$ " means the solute concentration is that of the bath.

Under these experimental conditions, diffusion potentials do not significantly contribute to solute distribution across the OMDVR wall and can be neglected (8). Thus, solute flux $(J)$ is defined in terms of solute concentration $(C)$, the permeability $(P)$, and the reflection coefficient $(\sigma)$ by the general expression

(Equation 8) $J=J(1-\sigma)\left\{\frac{C-C_{0} \exp (-\lambda)}{1-\exp (-\lambda)}\right\} \lambda=\frac{J(1-\sigma)}{\rho}$

When diffusion dominates over convection as the mode of solute transport $(\lambda<3)$, this expression simplifies. Due to the high diffusive permeabilities of the mouse OMDVR wall, it is readily shown that this applies to all of our experiments, so that

(Equation 9) $J=P_{i}\left(C_{1}-C_{s}\right)$

Thus, for these experiments, total volume and solute fluxes are defined by

\section{(Equation 10) \\ $J_{s}^{\top}=V_{v}\left[P_{n}\left(C_{m a r}-C_{m}\right)+\left(P_{n}+P_{n} \sigma_{j}\right)\left(C_{m}-C\right)\right]$}

(Equation 11) $J_{m=}^{\prime}=P_{\operatorname{mos}}\left(C_{n}-C_{\operatorname{man}}\right)$

(Equation 12) $J_{\mathrm{m}}^{*-1}=P_{\max }\left(C_{\mathrm{sis}}^{*}\right)$

(Equation 13) $J_{j}^{r}=P_{s}\left(\mathrm{C}-\mathrm{C}_{s}\right)$

(Equation 14) $J_{1 \mathrm{~m}}^{\pi}=P_{a}\left(C^{\prime}\right)$

To compute $\mathrm{P}_{\mathrm{f}}$, solute permeabilities measured in the absence of water flux were supplied as inputs, and these equations were iteratively integrated until predictions of apparent $\mathrm{P}_{\mathrm{f}}$ (defined below and in Table 1) yielded the experimentally measured collectate-to-perfusate volume marker ratio $R_{\mathrm{Dx}}(9)$. We relate $\mathrm{P}_{\mathrm{f}}$ to $\mathrm{AQP} 1$ and non-AQP1 pathways by applying the above equations to the specific protocols as follows.

All protocols. The diffusive permeabilities measured under zero volume flux conditions are expected to be that of the non-AQP1 pathway 2.

$A Q P 1^{+/+}, \mathrm{NaCl}$ as the driving solute, $P_{f}=P_{f 1}$. When $\mathrm{NaCl}$ was used to drive water flux across $A Q P 1^{+/+}$OMDVR, pathway 2 did not conduct water flux. This condition is achieved because $\mathrm{NaCl}$ is not osmotically active across pathway 2 (see Figures 2 and 4). In this case, $P_{f}=P_{f 1}$.

$A Q P 1^{+/+}$, raffinose as the driving solute, $P_{f}=P_{f 1}+\sigma_{i} P_{f 2}$. With raffinose, $\sigma_{\text {raf }}>0$ across pathway 2. Furthermore, because of the high permeability of the mouse OMDVR wall, $C_{\mathrm{Na}}=C_{\mathrm{Na}, \mathrm{B}}$; i.e., a significant transmural gradient of $\mathrm{NaCl}$ cannot be established across the OMDVR wall by AQP1 sieving. Thus, from equation $10, P_{f}=P_{f 1}+\sigma_{i} P_{f 2}$.

$A Q P 1^{-/-}, A Q P 1^{+/+}$with $p C M B S, i=$ urea, glucose, or raffinose as the driving solute, $P_{f}=\sigma_{i} P_{f 2}$. When AQP1 is blocked by pCMBS (see Figure 3 ) or is deleted (see Figure 2), $\mathrm{NaCl}$ fails to drive water flux across the OMDVR wall, but $\sigma_{i}>0$ because larger solutes are effective (see Figures 4-6). Again, due to the high permeability of the OMDVR wall, $C_{\mathrm{Na}}=C_{\mathrm{Na}, \mathrm{B}}$ so that $P_{f}=\sigma_{i} P_{f 2}$.

Expressions defining overall $\mathrm{P}_{\mathrm{f}}$ in terms of $\mathrm{P}_{\mathrm{f} 1}, \mathrm{P}_{\mathrm{f} 2}$, and the reflection coefficients of the pathways are provided in Table 1.

Statistical analysis. Except where otherwise specified, experimental results are reported as mean \pm SEM. Statistical comparisons use paired or unpaired Student's $t$ tests, ANOVA, and linear regression as appropriate.

\section{Results}

Effect of AQP1 deletion on OMDVR diameter. OMDVR were dissected from vascular bundles and perfused in vitro. As with rats, the vessels were readily identified and distinguished from thin limbs of Henle by their irregular cell spacing and the protrusion of pericyte cell bodies on the abluminal surface. Compared with rats, OMDVR from $A Q P 1^{+/+}$mice are similar in diameter but relatively thinwalled, with fewer pericytes per unit of vessel length. An interesting and unexpected finding is that $A Q P 1^{-/-}$ OMDVR are remarkably larger in diameter than are $A Q P 1^{+/+}$vessels (Figure 1). In addition, we observed that

\section{Table 1}

Definition of $\mathrm{P}_{\mathrm{f}}$ for various experimental protocols

\begin{tabular}{lcc}
\hline & \multicolumn{2}{c}{ Driving solute } \\
$\mathrm{NaCl}$ & Raffinose, glucose, urea \\
$A Q P 1^{+/+}$ & $P_{f}=P_{f 1}$ & $P_{f}=P_{f 1}+\sigma_{2, i} P_{f 2}$ \\
$A Q P 1^{+/+}, \mathrm{pCMBS}$ & $P_{f}=P_{f 1} \cong 0$ & $P_{f} \cong \sigma_{2, i} P_{f 2}$ \\
$A Q P 1^{-/-}$ & $P_{f}=0$ & $P_{f} \cong \sigma_{2, i} P_{f 2}$ \\
\hline
\end{tabular}

The assumptions involved in the derivation of these expressions (see Methods) are: first, that due to AQP1, pathway 1 has reflection coefficients of 1.0 to all solutes; second, pathway 2 has a reflection coefficient to $\mathrm{NaCl}$ of zero; and third, due to high mouse OMDVR permeability to $\mathrm{NaCl}$, for all experiments in which $\mathrm{NaCl}$ is not the driving solute, the concentration of $\mathrm{NaCl}$ in the lumen is equal to that in the bath. 


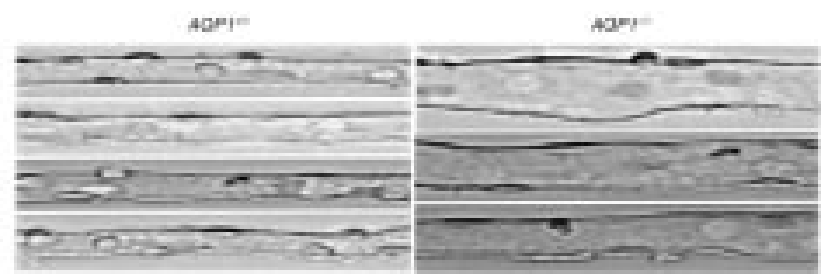

Figure 1

Light micrographs of OMDVR from $A Q P 1^{+/+}$mice and $A Q P 1^{-/-}$ mice. Four OMDVR from $A Q P 1^{+/+}$mice are shown in the left panel, and 3 OMDVR from $A Q P 1^{-/-}$mice are shown at right. Deletion of AQP1 leads to an increase in OMDVR diameter.

$A Q P 1^{-/-}$vessels are more easily freed from vascular bundles than are those from $A Q P 1^{+/+}$mice. Differences in ultrastructure attributable to AQP1 deletion have also been described in thin descending limbs of Henle (16).

OMDVR $P_{f}$ of AQP1-deficient mice. The effect of AQP1 deletion on $\mathrm{P}_{\mathrm{f}}$ measured with transmural $\mathrm{NaCl}$ gradients is shown in Figure 2. In these experiments, water efflux was driven by raising $\mathrm{NaCl}$ concentration in the bath from $150 \mathrm{nM}$ to $350 \mathrm{mM}$. The experimenter was blinded to mouse genotype for comparative transport measurements. Osmotic equilibration was calculated from chloride concentrations measured in the bath, perfusate, and collectate by microcolorimetry. OMDVR of $A Q P 1^{+/+}$mice had a $P_{\mathrm{f}}$ value of $1,015 \pm 156 \mu \mathrm{m} / \mathrm{s}$, a value similar to that reported in rats (8). In contrast, OMDVR from $A Q P 1^{+/}$ mice and $A Q P 1^{--}$mice had $\mathrm{P}_{\mathrm{f}}$ values of $548 \pm 142 \mu \mathrm{m} / \mathrm{s}$ and $9 \pm 4 \mu \mathrm{m} / \mathrm{s}$, respectively $\left(P<0.05, A Q P 1^{+/+} v s . A Q P 1^{+/}\right.$; $P<0.00001 A Q P 1^{+/+}$vs. $\left.A Q P 1^{-/-}\right)$. The failure of $\mathrm{NaCl}$ to drive water flux in $A Q P 1^{-/-}$vessels is not accounted for by rapid equilibration of $\mathrm{NaCl}$ across the vessel walls. Short vessel segments and high perfusion rates were used to minimize $\mathrm{NaCl}$ equilibration between bath and lumen. The fraction of the transmural chloride gradient at the perfusion end that remains at the collection end of the vessel is given by $R_{\text {chloride }}=(350-$ collectate chloride $) / 200$. In the experiment represented in Figure $2, R_{\text {chloride }}$ was 0.55 $\pm 0.08\left(A Q P 1^{+++}\right), 0.54 \pm 0.06\left(A Q P 1^{+/-}\right)$, and $0.63 \pm 0.04$ $\left(A Q P 1^{-/}\right)($mean $\pm \mathrm{SEM})$. Vessel diameters in these studies were $14.1 \pm 0.6 \mu \mathrm{m}\left(A Q P 1^{+/+}\right)$and $27 \pm 1.3 \mu \mathrm{m}\left(A Q P 1^{-/-}\right)(P$ $<0.05$, mean $\pm \mathrm{SEM}$ ); the increase in $A Q P 1^{-/-}$OMDVR surface area tends to blunt rather than amplify differences in overall water flux in these experiments.

$\mathrm{P}_{\mathrm{f}}$ was next compared in $A Q P 1^{+/+}$and $A Q P 1^{-/-}$mice in response to $\mathrm{NaCl}$ and raffinose gradients. Raffinose was more effective than was $\mathrm{NaCl}$ in driving water flux. In a series of $7 A Q P 1^{+/+}$OMDVR, mean $\mathrm{P}_{\mathrm{f}}$ with $\mathrm{NaCl}$ was $1,041 \pm 221 \mu \mathrm{m} / \mathrm{s}$. In those 7 vessels and in an additional 4 OMDVR $\left(n=11\right.$ total), $\mathrm{P}_{\mathrm{f}}$ with raffinose was $2,527 \pm 375 \mu \mathrm{m} / \mathrm{s}(P<0.001$, unpaired $t$ test $)$. An example of original data is shown in Figure 3a, where a 200 $\mathrm{mM}$ transmural gradient of raffinose was as effective as the larger $400 \mathrm{mOsm} / \mathrm{L} \mathrm{NaCl}$ gradient in inducing transmural water flux and concentrating the FITCDx volume marker in the collectate (Figure 3a, left).

The inhibitory effect of pCMBS was measured to compare raffinose and $\mathrm{NaCl}$ as driving solutes. Original data are shown in Figure 3a; data from many OMDVR are summarized in Figure 3, b and c. The original fluorescence data in Figure 3a (left) show that pCMBS strongly inhibits water permeability in OMDVR from $A Q P 1^{+/+}$mice. In a separate series of OMDVR $(n=6), \mathrm{P}_{\mathrm{f}}$ driven by $\mathrm{NaCl}$ and raffinose was measured before and after a 30-minute incubation with $2 \mathrm{mM}$ pCMBS, and again after a 5-minute incubation in $5 \mathrm{mM}$ DTT. Baseline $\mathrm{P}_{\mathrm{f}}$ was much higher with raffinose than with $\mathrm{NaCl}(2,215 \pm 289 \mu \mathrm{m} / \mathrm{s}$ vs. 1,184 $\pm 233 \mu \mathrm{m} / \mathrm{s}$, respectively; Figure $3 \mathrm{~b})$. $\mathrm{NaCl}$-driven water flux was reduced $94 \%$ by pCMBS $\left(\mathrm{P}_{\mathrm{f}}=71 \pm 22 \mu \mathrm{m} / \mathrm{s}\right)$, but pCMBS was less effective at reducing raffinose-driven water flux $\left(P_{\mathrm{f}}=917 \pm 249 \mu \mathrm{m} / \mathrm{s}\right)$. Five minutes of incubation with DTT restored water transport caused by $\mathrm{NaCl}$ $\left(\mathrm{P}_{\mathrm{f}}=1,016 \pm 150 \mu \mathrm{m} / \mathrm{s}\right)$ and raffinose $\left(\mathrm{P}_{\mathrm{f}}=1,789 \pm 285\right.$ $\mu \mathrm{m} / \mathrm{s})$, indicating that the inhibition was reversible and thus not related to a toxic effect of pCMBS.

Based on the above findings, we postulated that an additional, non-AQP1, mercurial-insensitive pathway conducts water flux driven by raffinose. To test this, $P_{f}$ was measured in AQP1-deficient OMDVR with raffinose before and after treatment with pCMBS. $P_{\mathrm{f}}$ driven by raffinose $(200 \mathrm{mM})$ in $11 \mathrm{AQP1^{-/- }}$ vessels was high $(1,104 \pm 153 \mu \mathrm{m} / \mathrm{s}$; Figure $3 \mathrm{c})$, and was similar to that of pCMBS-treated $A Q P 1^{+/+}$OMDVR $(917 \pm 249 \mu \mathrm{m} / \mathrm{s}$; Figure 3b). Raffinose-driven water flux in $A Q P 1^{-/-}$OMDVR was insensitive to a 30-minute incubation with $2 \mathrm{mM}$ pCMBS (Figure 3, a and c). These results provide direct evidence for an AQP1-independent mercurial-insensitive water pathway.

Solute size dependence of osmosis in OMDVR from AQP1-/mice. The preceding experiments showed that raffinose, but not $\mathrm{NaCl}$, drives water flux across the OMDVR wall of $A Q P 1^{-/-}$mice, and that this pathway is mercurial insensitive. The AQP1-independent pathway might be solute restrictive (of high reflection coefficient and small pore radius) or nonrestrictive (with high $\mathrm{P}_{\mathrm{f}}$, a low reflection coefficient, and relatively large pore radius). In the latter case, the apparent $P_{\mathrm{f}}$ is predicted to increase with the Stokes-Einstein radius of the driving solute. To test this, $\mathrm{P}_{\mathrm{f}}$ of $A Q P 1^{-/-}$OMDVR was measured with solutes of varying molecular weights. Isotopes of these solutes were added to the perfusate to mon- 
itor osmotic equilibration (see Methods). In individual OMDVR, we measured $\mathrm{P}_{\mathrm{f}}$ using pairs of solutes whose radioactivities could be distinguished by dual isotope counting (3): ${ }^{22} \mathrm{Na}$ and $\left[{ }^{3} \mathrm{H}\right]$ raffinose $(n=8),\left[{ }^{14} \mathrm{C}\right]$ urea and $\left[{ }^{3} \mathrm{H}\right]$ raffinose $(n=8)$, and $\left[{ }^{3} \mathrm{H}\right]$ glucose and $\left[{ }^{14} \mathrm{C}\right]$ urea $(n=$ $7)$. Raffinose $\left(\mathrm{P}_{\mathrm{f}}=833 \pm 107 \mu \mathrm{m} / \mathrm{s}\right)$ induced more water flux across the $A Q P 1^{-/}$OMDVR wall than $\operatorname{did} \mathrm{NaCl}\left(\mathrm{P}_{\mathrm{f}}=\right.$ $60 \pm 25 \mu \mathrm{m} / \mathrm{s})$. Glucose (400 mM bath, $\left.\mathrm{P}_{\mathrm{f}}=484 \pm 44 \mu \mathrm{m} / \mathrm{s}\right)$ and urea (400 mM bath, $\left.\mathrm{P}_{\mathrm{f}}=162 \pm 32 \mu \mathrm{m} / \mathrm{s}\right)$ were also more effective than was $\mathrm{NaCl}$ in driving water movement. All water transport measurements are summarized in Figure 4 along with an additional group of $A Q P 1^{-/-}$vessels that were not fixed with GA in which $\mathrm{P}_{\mathrm{f}}$ was also determined $(n=8)$. The latter was accomplished by minimizing exposure of endothelia to large gradients by using small collectate volumes and short collection times (bath raffinose $=200 \mathrm{mM}$ ). In the absence of GA fixation, $\mathrm{P}_{\mathrm{f}}$ was 998 $\pm 136 \mu \mathrm{m} / \mathrm{s}(n=21)$, whereas with fixation, $\mathrm{P}_{\mathrm{f}}$ was $1,204 \pm$ $157 \mu \mathrm{m} / \mathrm{s}(n=8)$, values that are not significantly different. An increase in the area of light collection was also ruled out as a possible artifact. High concentrations of solutes might change the refractive index of the bath, leading to alteration of light collection by the microscope objective. When a water-impermeable glass capillary of similar dimensions was substituted for an OMDVR, the collectate fluorescence did not change when $400 \mathrm{mM}$ glucose or $200 \mathrm{mM}$ raffinose was exchanged into the bath.

Small solute transport by the OMDVR wall. The diffusive permeabilities of the OMDVR wall to ${ }^{22} \mathrm{Na},\left[{ }^{14} \mathrm{C}\right]$ urea, $\left[{ }^{3} \mathrm{H}\right]$ raffinose, and $\left[{ }^{14} \mathrm{C}\right]$ glucose were required for $\mathrm{P}_{\mathrm{f}}$ determinations. In addition, the permeability to $\left[{ }^{14} \mathrm{C}\right]$ inulin was also measured as part of molecular sieving experiments. The permeabilities are summarized in Figure 5. $\mathrm{NaCl}$ and urea permeabilities are of direct relevance to countercurrent exchange by vasa recta. Permeability to urea is quite high, probably due to expression of an endothelial urea transporter $(3-5,17)$. Solute permeabilities generally exceed those previously reported in rats by factors of 2-3 (refs. 3-5).

We tested whether the non-AQP1, mercurial-insensitive pathway is capable of restricting solute transport by molecular sieving. Vessels were perfused with FITCDx and 2 isotopes, either $\left[{ }^{3} \mathrm{H}\right]$ raffinose and ${ }^{22} \mathrm{Na}$ or $\left[{ }^{3} \mathrm{H}\right]$ raffinose and $\left[{ }^{14} \mathrm{C}\right]$ inulin. Permeability to both tracers was measured under zero flux conditions by dual isotope counting $(3,4,9)$. Subsequently, water flux was induced by adding $200 \mathrm{mM}$ raffinose to the bath. In all cases, raffinose drove water efflux, as demonstrated by a fall in the collection rate $\left(Q_{c}\right)$ and a rise in the collectate-to-perfusate FITCDx ratio $\left(R_{\mathrm{Dx}}\right)$ (Figure 6, a and b). $R_{\mathrm{Na}}$ changed little during water efflux (Figure 6c), but $R_{\text {raf }}$ and $R_{\mathrm{IN}}$ increased (Figure 6 , $\mathrm{d}$ and $\mathrm{e})$. This demonstrates some degree of molecular sieving. Mathematical simulations such as these were used previously to estimate reflection coefficients of rat OMDVR to ${ }^{22} \mathrm{Na}$ and $\left[{ }^{3} \mathrm{H}\right]$ raffinose (9). However, similar simulations of the current data in mouse OMDVR do not yield reliable reflection coefficient values because of the substantially higher solute permeabili- ties in mouse compared with rat. The increase of $R_{\mathrm{raf}}$ and $R_{\mathrm{IN}}$ with volume efflux, however, shows qualitatively that $\sigma_{\text {raf }}>0$ and $\sigma_{\text {in }}>0$ in $A Q P 1^{-/-}$OMDVR.

The role of $A Q P 1$ in the maintenance of medullary interstitial osmolar gradients. We recently reported mathematical simulations of the renal medullary microcirculation that takes

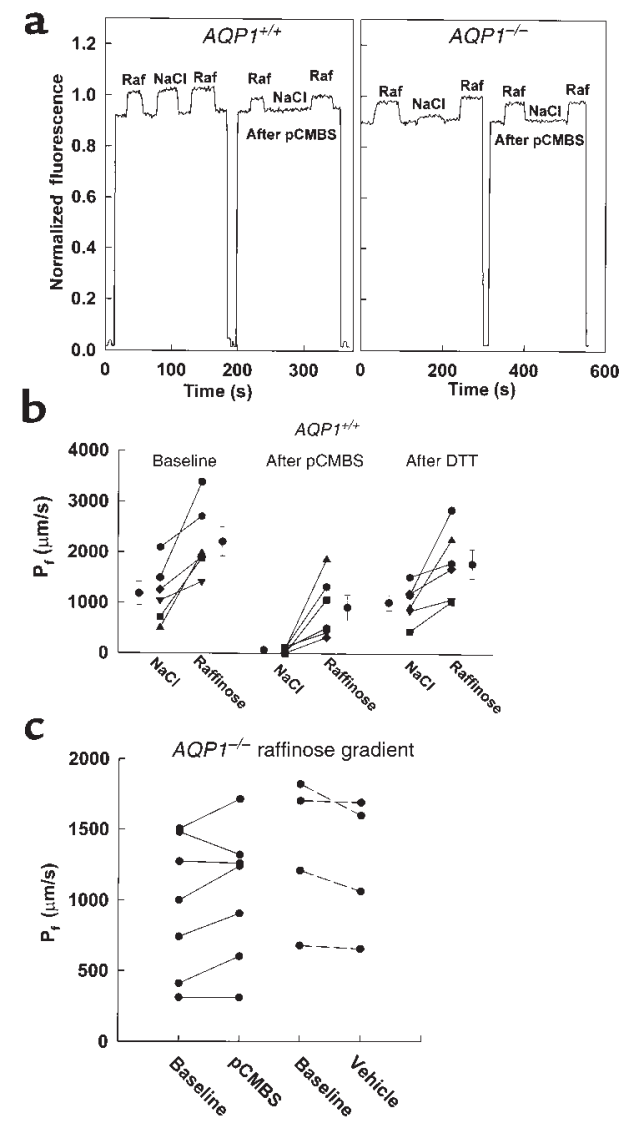

Figure 3

Osmotic water transport across $A Q P 1^{+/+}$and $A Q P 1^{-/-}$OMDVR wall. (a) Left: Collectate fluorescence reversibly rose as raffinose or $\mathrm{NaCl}$ was added to and then removed from the bath of a microperfused $A Q P 1^{+/+}$ OMDVR. Despite the much larger transmural $\mathrm{NaCl}$ gradient (400 $\mathrm{mOsm} / \mathrm{L})$, raffinose $(200 \mathrm{mM})$ concentrated the FITCDx volume marker with equal effectiveness. After 30 minutes of incubation in $2 \mathrm{mM}$ $\mathrm{pCMBS}$, raffinose continued to drive water efflux, but $\mathrm{NaCl}$ was ineffective. Right: Collectate fluorescence reversibly rose as raffinose was added to and then removed from the bath, but $\mathrm{NaCl}$ was ineffective at driving water movement across the wall of a microperfused $A Q P 1^{-1-}$ OMDVR. Raffinose-driven water efflux was not reduced by pCMBS. Raf, raffinose. (b) The effect of $\mathrm{PCMBS}$ on $\mathrm{P}_{\mathrm{f}}$ of $A Q P 1^{+/+}$OMDVR was tested. Paired measurements of $\mathrm{P}_{\mathrm{f}}$ were obtained using transmural raffinose and $\mathrm{NaCl}$ gradients in random order. In all vessels, raffinose was more effective than was $\mathrm{NaCl}$ at inducing osmotic water movement $(P<0.05)$. After 30 minutes of incubation with pCMBS $(2 \mathrm{mM}), P_{f}$ measured with $\mathrm{NaCl}$ was reduced to nearly zero, but $\mathrm{P}_{\mathrm{f}}$ measured with raffinose was only partly inhibited $(P<0.05$ for both comparisons). A 5-minute treatment with DTT $(5 \mathrm{mM})$ reversed the pCMBS effects. (c) The effect of pCMBS of inhibiting water flux across the $A Q P 1^{-/-}$OMDVR wall was tested. $\mathrm{P}_{\mathrm{f}}$ was measured in OMDVR from $A Q P 1^{-1-}$ mice as water efflux was driven by the addition of raffinose $(200 \mathrm{mM})$ to the bath. Vessels were incubated for 30 minutes in pCMBS $(2 \mathrm{mM}, n=7)$ or vehicle $(n=4)$. The pathway across which raffinose drives water efflux in AQP1--- OMDVR wall is insensitive to mercurials. 


\section{Figure 4}

Summary of measurements of $\mathrm{P}_{\mathrm{f}}$. All $\mathrm{P}_{\mathrm{f}}$ measurements are summarized (ordinate, mean $\pm \mathrm{SEM}$ ) for $A Q P 1^{-/-}$ mice (left) and $A Q P 1^{+/+}$mice (right). The solute used to drive water movement is shown on the abscissa. GAfixed vessels were used except for $8 A Q P 1^{-/-}$vessels. $P_{f}$ was the same when measured with raffinose whether or not the GA fixation step was included. For purposes of calculating $P_{f}$, the influx of the solute used to drive water movement was most often calculated by measuring lumen-to-bath efflux of the equivalent isotope and simulating the experiment with a mathematical model (see Methods). In $A Q P 1^{+/+}$OMDVR, osmolar equilibration was monitored in 2 ways: by measuring efflux of ${ }^{22} \mathrm{Na}(n=14)$ or measuring influx of $\mathrm{NaCl}$ by microassay of collectate chloride ( $n=11$; see Figure 2 ). These approaches yielded similar values. Note that the sum of $\mathrm{P}_{\mathrm{f}}$ measured with $\mathrm{NaCl}$ in $\mathrm{AQP1} 1^{+/+}$vessels (AQP1 only) and $\mathrm{P}_{\mathrm{f}}$ measured with raffinose in $A Q P 1^{-/-}$vessels (non-AQP1 only) is equal to $\mathrm{P}_{\mathrm{f}}$ measured with raffinose in $A Q P 1^{+/+}$OMDVR (AQP1 and non-AQP1 pathways). The number of vessels in each group is shown on the figure beside the corresponding error bar.

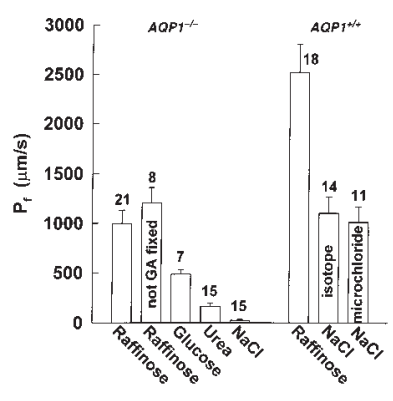

into account DVR destined to perfuse the inner medulla as well as the complex array of transport pathways described in rat OMDVR (18). These include paracellular and transcellular transport of water, transport of solutes via paracellular diffusion, and transcellular urea transport by an endothelial facilitated carrier. In that model, the supply of solutes and water to the interstitium by the loops of Henle and collecting duct were described by generation terms that define their rates of appearance. The model predicted the magnitude of corticomedullary interstitial osmolar gradients that are achieved in the presence of the vascular countercurrent exchanger. Here we used the basal parameters defined in the rat as inputs to the model, but systematically varied DVR $P_{\mathrm{f}}$ from 1,000 to $0 \mu \mathrm{m} / \mathrm{s}$. This is the mathematical equivalent of graded AQP1 deletion in the rat. The result is illustrated in Figure 7, where the predicted interstitial osmolality is shown as a function of dimensionless corticomedullary axis, $x / L$. Deletion of AQP1 leads to substantial reduction of interstitial osmolality. Equivalent simulations cannot be performed for the mouse because measurements of the many required parameter inputs have not been obtained.

\section{Discussion}

As blood flows from the corticomedullary junction toward the papillary tip, DVR plasma equilibrates with the renal medullary interstitium by water efflux and solute influx. Efflux of water across the DVR wall requires outwardly directed driving forces and a water conductive pathway. Sanjana and colleagues (7) showed that hydraulic pressure in the DVR lumen is too low to drive water efflux against the opposing plasma oncotic pressure. They recognized, however, that the lag in equilibration of DVR plasma with the medullary interstitium creates transmural $\mathrm{NaCl}$ and urea gradients that supply an additional outwardly directed osmotic driving force. The hypothesis that $\mathrm{NaCl}$ and urea drive water efflux across the DVR wall requires a pathway across which such small hydrophilic solutes can exert effective osmotic pressure. One possible route has been identified as the AQP1 water channel. Immunochemical studies have shown that endothelial AQP1 expression is sufficient to impart significant $P_{\mathrm{f}}$ to the DVR wall $(2,8$, 19). Inhibition of AQP1 in microperfused rat OMDVR with pCMBS reduces diffusional water permeability (2), and has been shown to remarkably reduce osmotic water flux driven by transmural gradients of $\mathrm{NaCl}$ (8). The AQP1-deficient mouse has provided the opportunity to definitively test the hypothesis that $\mathrm{AQP} 1$ is the route that conducts osmotic water efflux across the DVR wall in response to transmural gradients of hydrophilic solutes. We found that AQP1 deletion eliminates nearly all $\mathrm{NaCl}$-driven water flux across the wall of mouse OMDVR (Figure 2), but that other solutes, including urea, are able to drive water flux by at least 1 separate mercurial-insensitive pathway (Figures 3 and 4).

An unexpected finding of this study was that OMDVR dissected from $A Q P 1^{-/-}$mice are substantially larger than those obtained from wild-type or heterozygotic mice. Deletion of AQP1 might lead to remodeling of the microvessel wall, but this has not been observed in continuous vessels of other organ beds. Alternately, this may be the first example of DVR remodeling as a means of long-term adaptation. Using cortical micropuncture, Schnermann et al. (11) have shown that reabsorption by the accessible proximal tubule of superficial nephrons is reduced from $48 \%$ to $26 \%$ of glomerular filtrate after AQP1 deletion. Despite this, distal delivery of filtrate in superficial nephrons was not increased, because of a marked reduction of single nephron glomerular filtration rate (SNGFR) attributable to tubuloglomerular feedback (TGF). Of note, the reduction of superficial SNGFR $(\sim 50 \%)$ was greater than the reduction in whole kidney GFR ( $30 \%)$, suggesting a smaller effect of TGF on deep nephrons whose loops of Henle penetrate to the inner medulla. Because papillary micropuncture studies have not been performed, the effects on medullary volume uptake of deletion of AQP1 from the proximal convoluted tubule and thin descending limbs of all populations of

\section{Figure 5}

Summary of diffusive permeabilities of mouse OMDVR. All measurements of diffusional permeabilities to the tracers shown on the abscissa are summarized (mean $\pm \mathrm{SEM}$ ). In both $A Q P 1^{+/+}$ OMDVR and $A Q P 1^{-1-}$ OMDVR, permeabilities were uniformly high. The number of vessels in each group is shown on the figure beside the corresponding error bar.

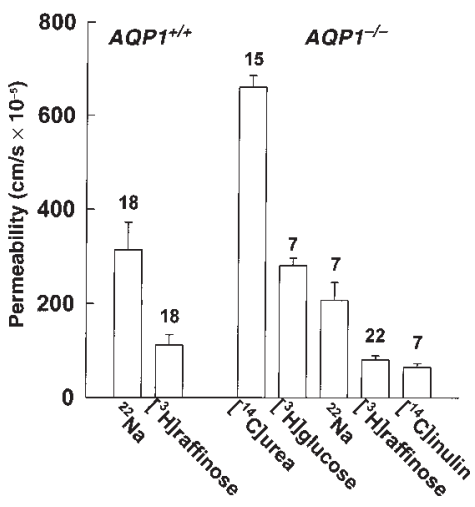




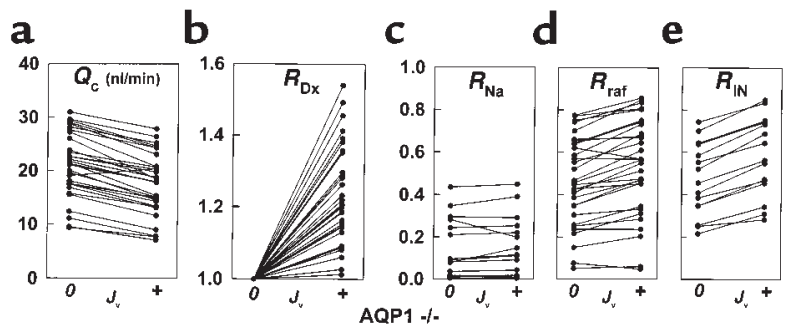

Figure 6

Molecular sieving of $\left[{ }^{3} \mathrm{H}\right]$ raffinose and $\left[{ }^{14} \mathrm{C}\right]$ inulin by $A Q P 1^{-/-}$ OMDVR. To demonstrate molecular sieving across the non-AQP1 pathway, water efflux was driven by adding raffinose $(200 \mathrm{mM})$ to the bath of $A Q P 1^{-/-}$vessels perfused with ${ }^{22} \mathrm{Na},\left[{ }^{3} \mathrm{H}\right]$ raffinose, or $\left[{ }^{14} \mathrm{C}\right]$ inulin. (a and $\mathbf{b}$ ) Water efflux occurred in response to the raffinose gradient as documented by a fall in collection rate $\left(Q_{c}\right)$ and a rise in $R_{\mathrm{Dx} \text {. }}$ (c-e) Collectate-to-perfusate activity ratios of the tracers $\left(R_{\mathrm{Na}}, R_{\mathrm{raf}}\right.$, and $\left.R_{\mathrm{IN}}\right)$ were measured during zero volume flux $\left(J_{\mathrm{v}}=0\right)$ and raffinose-driven volume flux $\left(J_{v}>0\right)$. Compared with $J_{v}=0, R_{\text {raf }}$ and $R_{\mathbb{N}}$ increased when $J_{v}=+(P<0.05)$, demonstrating molecular sieving $\left(\sigma_{\text {raf }}\right.$ and $\left.\sigma_{\text {in }}>0\right)$.

nephrons remains uncertain. $A Q P 1$ knockout mice have markedly reduced urinary concentrating ability, but this does not provide insight into the magnitude of reabsorption from the collecting duct. For example, Jamison et al. showed that more volume reabsorption occurs across the papillary collecting duct during water diuresis than occurs during hydropenia $(20,21)$. It remains a possibility that the increase in OMDVR diameter (Figure 1) in AQP1 knockouts is an adaptive response to a greater need for blood flow to recover salt and water from the medullary interstitium. The renal medulla is a hypoxic environment. Redistribution of blood flow from superficial to deep nephrons has been described in hypovolemic states (22, 23). The chronic extracellular volume depletion induced by AQP1 deletion in knockout mice might result in enhanced perfusion of the medulla to maintain tissue oxygenation. It is inviting to speculate that the increase in OMDVR diameter of $A Q P 1^{-1-}$ OMDVR serves to reduce the resistance to inflow of blood to the renal medulla. At present, the relative contributions to overall arteriovenous resistance of afferent and efferent arterioles vs. OMDVR is not known, so definitive conclusions cannot be drawn.

$\mathrm{P}_{\mathrm{f}}$ of the OMDVR wall was determined by established computational procedures described in prior studies that were modified as described in Methods. These experiments showed that at least 2 pathways conduct water flux across OMDVR in response to gradients of small solutes. One is AQP1 and the other is insensitive to PCMBS. The derivation in Methods (summarized in Table 1) shows the relationship between $P_{f}$ (see Figures 2-4) and the characteristics of these pathways. The observation that $\mathrm{NaCl}$-driven water flux across the OMDVR wall is eliminated by AQP1 deletion supports the conclusion that AQP1 is the sole route when $\mathrm{NaCl}$ is the driving solute. This fits well with the observation that pCMBS treatment markedly reduces $\mathrm{NaCl}$-driven water flux

\section{Figure 7}

Effect of AQP1 deletion on predicted renal medullary interstitial osmolality. The predicted interstitial osmolality is shown as a function of corticomedullary axis (corticomedullary junction: $x / L=0$; papillary tip: $x / L=$ 1) for various values of DVR $P_{f}$. AQP1 expression in OMDVR is predicted to enhance concentrating ability by mediating water efflux from DVR to AVR, secondarily reducing blood flow to the papillary tip.

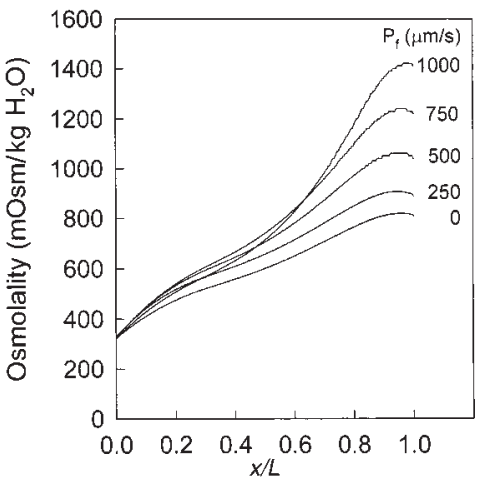


centrating mechanism. Transmural $\mathrm{NaCl}$ and urea gradients drive water flux from the DVR lumen to the medullary interstitium in the hydropenic kidney across AQP1, thereby shunting blood flow from DVR to ascending vasa recta (AVR) in the outer medulla. The effect of this is to reduce blood flow to the deepest portions of the microvascular exchanger, which is expected to enhance the efficiency of microvascular exchange in the inner medulla by reducing solute washout. A similar conclusion was reported by Thomas (25).

Mathematical models of the urinary concentrating mechanism have generally failed to predict the osmolalities achieved by rodents. Jen and Stephenson have proposed and predicted that accumulation of an additional osmolyte could augment water removal from the thin descending limb and enable models to predict the appropriate concentrating ability (26). Recently, Thomas suggested that lactate accumulation might serve such a role (27). If such an osmolyte is present, it would probably increase microvascular exchanger efficiency in the inner medulla by enhancing water removal from the DVR, driving efflux across both the AQP1 and non-AQP1 pathways defined in this study.

Endothelial cells in a variety of other organ beds including cornea, skeletal muscle, mesentery, lung, and salivary glands express AQP1 (28-30). The physiologic role in those locations is uncertain. In lung, where AQP1 is expressed in microvessels lining alveolar and distal airways, AQP1 deletion resulted in a 10-fold decrease in osmotically driven water permeability between the airspace and capillary compartments, and a smaller decrease in hydrostatically driven water transport (12). In contrast, deletion of AQP1 in microvascular endothelia of salivary gland did not affect saliva fluid production, whereas AQP5 deletion in salivary gland epithelial cells had a marked effect on saliva production (31). Thus the expression of AQP1 in microvascular endothelia does not ensure that it has an important physiologic function.

In summary, the principal finding of this study is that AQP1 deletion reduces $P_{f}$ of mouse OMDVR to nearly zero when transmural water flux is driven by gradients of $\mathrm{NaCl}$ (Figures 2 and 3), and that $\mathrm{P}_{\mathrm{f}}$ attributable to AQP1 is approximately $1,100 \mu \mathrm{m} / \mathrm{s}$ (Figure 4). OMDVR are remodeled and become larger when AQP1 is deleted. In addition to the AQP1 pathway, small hydrophilic solutes slightly larger than $\mathrm{NaCl}$ can drive water flux across a mercurial-insensitive pathway with an effectiveness that increases with molecular weight (Figure 4). Mathematical simulation of microvascular exchanger function supports the hypothesis that DVR expression of AQP1 enhances medullary interstitial osmolar gradients (Figure 7) by providing a route for volume efflux that shunts blood flow from DVR to AVR, secondarily reducing blood flow to the inner medulla.

\section{Acknowledgments}

This study was supported by National Institutes of Health grants DK-42495, HL-62220, DK-35124, HL-
59198, HL-60288, and DK-43840.

1. Pallone, T.L., Robertson, C.R, and Jamison, R.L. 1990. Renal medullary microcirculation. Physiol. Rev. 70:885-920.

2. Nielsen, S., et al. 1995. Aquaporin CHIP water channels in short and long loop descending thin limb and in descending vasa recta in rat kidney. Am. J. Physiol. 268:F1023-F1037.

3. Pallone, T.L., Nielsen, S., Silldorff, E.P., and Yang, S. 1995. Diffusive transport of solute in the rat medullary microcirculation. Am. J. Physiol. 269:F55-F63.

4. Pallone, T.L., Work,J., Myers, R.L., and Jamison, R.L. 1994. Transport of sodium and urea in renal outer medullary vascular bundles. J. Clin. Invest. 93:212-222

5. Pallone, T.L. 1994. Characterization of the urea transporter in outer medullary descending vasa recta. Am. J. Physiol. 267:R260-R267.

6. Turner, M.R, and Pallone, T.L. 1997. Hydraulic and diffusional permeabilities of isolated outer medullary descending vasa recta from the rat. Am.J.Physiol. 272:H392-H400.

7. Sanjana, V.M., Johnston, P.A., Robertson, C.R., and Jamison, R.L. 1976. An examination of the transcapillary water flux in the renal medulla. Am.J.Physiol. 231:313-318.

8. Pallone, T.L., Kishore, B.K., Nielsen, S., Agre, P., and Knepper, M.A. 1997. Evidence that aquaporin 1 mediates $\mathrm{NaCl}$-induced water flux across descending vasa recta. Am. J. Physiol. 272:F587-F596.

9. Pallone, T.L., and Turner, M.R. 1997. Molecular sieving of small solutes by outer medullary descending vasa recta. Am. J. Physiol. 272:F579-F586.

10. Ma, T., et al. 1998. Severely impaired urinary concentrating ability in transgenic mice lacking aquaporin-1 water channels. J. Biol. Chem. 273:4296-4299.

11. Schnermann, J., et al. 1998. Defective proximal tubular fluid reabsorption in transgenic aquaporin-1 null mice. Proc. Natl. Acad. Sci. USA. 95:9660-9664.

12. Bai, C.X., et al. 1999. Lung fluid transport in aquaporin-1 and aquaporin-4 knockout mice. J. Clin. Invest. 103:555-561.

13. Imai, M., Yasoshima, K., and Yoshitomi, K. 1990. Mechanism of water transport across the upper portion of the descending thin limb of long-looped nephron of hamsters. Pflugers Arch. 415:630-637.

14. Wade, J.B., and Kachadorian, W.A. 1988. Cytochalasin B inhibition of toad bladder apical membrane responses to ADH. Am. J. Physiol. 255:C526-C530.

15. Pallone, T.L. 1994. Vasoconstriction of outer medullary descending vasa recta by angiotensin II is modulated by prostaglandin $\mathrm{E}_{2}$. Am. J. Physiol. 266:F850-F857.

16. Chou, C.-L., et al. 1999. Reduced water permeability and altered ultrastructure in thin descending limbs of Henle in aquaporin-1 null mice. J. Clin. Invest. 103:491-496.

17. Tsukaguchi, H., Shayakul, C., Berger, U.V., and Hediger, M.A. 1998. Urea transporters in kidney: molecular analysis and contribution to the urinary concentrating process. Am. J. Physiol. 275:F319-F324.

18. Edwards, Á., DeLong, M.J., and Pallone, T.L. 2000. Interstitial water and solute recovery by inner medullary vasa recta. Am. J. Physiol. In press.

19. Nielsen, S., Smith, B.L., Christensen, E.I., and Agre, P. 1993. Distribution of the aquaporin CHIP in secretory and resorptive epithelia and capillary endothelia. Proc. Natl. Acad. Sci. USA. 90:7275-7279.

20. Jamison, R.L., Buerkert, J., and Lacy, F.B. 1971. A micropuncture study of collecting tubule function in rats with hereditary diabetes insipidus. J. Clin. Invest. 50:2444-2452.

21. Jamison, R.L., and Lacy, F.B. 1972. Evidence for urinary dilution by the collecting tubule. Am. J. Physiol. 223:898-902.

22. McNay, J.L., and Abe, Y. 1970. Pressure dependent heterogeneity of renal cortical blood flow in dogs. Circ. Res. 27:571-587.

23. Slotkoff, L.M., Logan, A., Jose, P., D'Avella, J., and Eisner, G.M. 1971. Microsphere measurement of intrarenal circulation of the dog. Circ. Res. 28:158-166.

24. Fettiplace, R., and Haydon, D.A. 1980. Water permeability of lipid membranes. Physiol. Rev. 60:510-550.

25. Thomas, S.R. 1998. Cycles and separations in a model of the renal medulla. Am. J. Physiol. 275:F671-F690.

26. Jen, J.E., and Stephenson, J.L. 1994. Externally driven countercurrent multiplication in a mathematical model of the urinary concentrating mechanism in the renal inner medulla. Bull. Math. Biol. 56:491-514.

27. Thomas, S.R. 1999. Net osmole production by inner medullary glycolysis could contribute importantly to the renal concentrating mechanism. Institute for Mathematics and Its Applications, Membrane Transport and Renal Physiology Workshop. Newsletter 270.

28. Hasegawa, H., Lian, S.-C., Finkbeiner, W.E., and Verkman, A.S. 1994 Extrarenal distribution of CHIP28 water channels by in situ hybridization and antibody staining. Am. J. Physiol. 266:C893-C903.

29. Carter, E.P., Ölveczky, B.P., Matthay, M.A., and Verkman, A.S. 1998. High microvascular endothelial water permeability in mouse lung measured by a pleural surface fluorescence method. Biophys. J. 74:2121-2128.

30. Echevarria, M., et al. 1993. Cultured bovine corneal endothelial cells express CHIP28 water channels. Am. J. Physiol. 265:C1349-C1355.

31. Ma, T., et al. 1999. Defective secretion of saliva in transgenic mice lacking aquaporin-5 water channels. J. Biol. Chem. 274:20071-20074. 